\title{
SYNTHESIS, CHARACTERIZATION AND THERMAL STUDIES OF WHOLLY AROMATIC POLY(IMIDE- AMIDES) CONTAINING SI AND/OR GE IN THE MAIN CHAIN
}

\author{
L.H. TAGLE*, C.A. TERRAZA, P.A. ORTIZ, A. TUNDIDOR-CAMBA
}

Facultad de Química, Pontificia Universidad Católica de Chile, P.O. Box 306, Santiago, CHILE

(Received: June 20, 2011 - Accepted: August 2, 2011)

\begin{abstract}
Poly(imide-amides) (PIAs) containing the heteroatoms Si and/or Ge in the main chain were obtained from diacids, which were synthesized from trimellitic anhydride and the diamines bis(4-aminophenyl)diphenylsilane or bis(4-aminophenyl)diphenylgermane. With the same diamines the polymers containing the heteroatoms $\mathrm{Si}$ and $\mathrm{Ge}$ in the main chain were obtained. Polymers were soluble in aprotic polar solvents and characterized by $\mathrm{IR}$ and ${ }^{1} \mathrm{H},{ }^{13} \mathrm{C}$ and ${ }^{29} \mathrm{Si} \mathrm{NMR}$ spectroscopy, and the results were in agreement with the proposed structures. Low inherent viscosity values $\left(\eta_{\text {inh }}\right)(0.04-0.12 \mathrm{dL} / \mathrm{g})$ were obtained, indicating the presence of oligomeric species. The Tg values were obtained by differential scanning calorimetry (DSC), and the results did not show a relation with the nature of the heteroatoms, in the sense that the polymers with Si should have higher Tg values than those with Ge due to the lower volume of the former atom. Also, the low values of $\eta_{\text {inh }}$ associated to low molecular weight species, have important influence on $\mathrm{Tg}$ values. The thermal decomposition temperatures were obtained by dynamic thermogravimetry. These analyses showed that the highest thermal decomposition temperature (TDT) values were obtained for PIA-II and PIA-III with Si and Ge in the repeating unit, and the lowest TDT values with two Si atoms in the unit.
\end{abstract}

Keywords: poly(imide-amides), silicon, germanium, thermal stability, glass transition temperature.

\section{INTRODUCTION}

Poly(imides) and poly(amides) are normally condensation polymers derived from diacids or dianhydrides and diamines that have high thermal stability. The main problem of this kind of polymers is the lack of solubility in common organic solvents, being the intermolecular bonding energy developed through hydrogen bonding, and through dipole-dipole interactions, the major parameters that contribute to the insolubility (1). Also, wholly aromatic poly(imides) have been used as important materials due to their high thermal stability and other properties, including chemical stability $(2,3)$.

Bruma et al. have reported that the presence of $\mathrm{C}-\mathrm{Si}$ bonds can improve the solubility of the polymers due to the ionic character of this bond (4). Other effect of the introduction of C-Si or C-Ge bonds in a polymeric chain is the possible increasing of the thermal stability due to the ionic character of these bonds. This is because silicon and germanium atoms are less electronegative than carbon, however, the energy of the $\mathrm{C}-\mathrm{C}, \mathrm{C}-\mathrm{Si}$ and $\mathrm{C}-\mathrm{Ge}$ bonds, is very similar (5).

On the other hand, poly(imide-amides) are alternative materials, which offer the thermal stability of the poly(imides) and the solubility and processability of the poly(amides) (6-8).

Silicon-containing polymers have been important to our research group, and we have described the synthesis of poly(amides) (9) and poly(imideamides) (10), showing good thermal stability depending on the structure of the repeating unit. On the other hand, germanium-containing polymers in which the Ge atom is bonded to four organic groups, have not received much attention with the exception of our works (11-15). Also we reported the synthesis of several other kinds of condensation polymers, such as poly(carbonates), poly(thiocarbonates) and poly(esters), in which the thermal properties were strongly influenced by the nature of the heteroatom and the organic groups bonded to them. Many of these polymers showed good thermal properties and even some of them were thermally stable (16).

In this work we described the synthesis and characterization of poly(imideamides) (PIAs) derived from trimellitic anhydride, which were reacted with the diamines bis(4-aminophenyl)diphenylsilane or germane in order to obtain two diacids. These diacids were polymerized with the respective diamines, in order to obtain four new PIAs with different combinations of the two heteroatoms.

\section{EXPERIMENTAL PART}

\section{Materials}

Trimellitic acid (1,2,4-benzenetricarboxylic anhydride), $\left(\mathrm{C}_{6} \mathrm{H}_{5}\right)_{2} \mathrm{SiCl}_{2}$, $\left(\mathrm{C}_{6} \mathrm{H}_{5}\right)_{2} \mathrm{GeCl}_{2}$, and 4-bromo- $N, N$-bis(trimethylsilyl)aniline, triphenyl phosphite (TTP) and anhydrous $\mathrm{CaCl}_{2}$ were obtained from Aldrich Chemical
(Milwaukee, WI) and used without further purification. Solvents (Aldrich Chemical, Milwaukee, WI) were dried over sodium previous to use. All other reagents and solvents were purchased commercially as analytical-grade and used without further purification.

\section{Instrumentation}

The IR spectra ( $\mathrm{KBr}$ pellets) were recorded on a Perkin-Elmer (Fremont CA) 1310 spectrophotometer over a $450-4000 \mathrm{~cm}^{-1}$ range. ${ }^{1} \mathrm{H},{ }^{13} \mathrm{C}$ and ${ }^{29} \mathrm{Si}$ NMR spectra were carried out on a $400 \mathrm{MHz}$ instrument (Bruker AC-200) using DMSO- $\mathrm{d}_{6}$ or acetone- $\mathrm{d}_{6}$ as solvents and TMS as the internal standard. Viscosimetric measurements were made in a Desreux-Bischof type dilution viscosimeter at $25^{\circ} \mathrm{C}(\mathrm{c}=0.3 \mathrm{~g} / \mathrm{dL})$. Tg values were obtained with a MettlerToledo (Greifensee, Switzerland) DSC 821 calorimetric system $\left(20^{\circ} \mathrm{C} \mathrm{min}{ }^{-1}\right.$ under $\mathrm{N}_{2}$ flow) from the second cycle of heating. Thermogravimetric analyses were carried out in a Mettler (Switzerland) TA-3000 calorimetric system equipped with a TC-10A processor, and a TG-50 thermobalance with a Mettler MT5 microbalance. Samples of 6-10 mg were placed in a platinum sample holder and the thermogravimetric measurements were carried out between 30 ${ }^{\circ} \mathrm{C}$ and $800{ }^{\circ} \mathrm{C}$ with a heating rate of $10{ }^{\circ} \mathrm{C} \mathrm{min}-1$ under $\mathrm{N}_{2}$ flow. Elemental analysis were made on a Fisons EA 1108-CNS-O equipment.

\section{Monomers}

The monomers, 2-(4-((4-(5-carboxy-1,3-dioxoisoindolin-2-yl)phenyl) diphenylsilyl)phenyl)-1,3-dioxoisoindoline-5-carboxylic acid (I-Si) and 2-(4-((4-(5-carboxy-1,3-dioxoisoindolin-2-yl)phenyl)diphenylgermyl) phenyl)-1,3-dioxoisoindoline-5-carboxylic acid (I-Ge), were obtained according to the following general procedure (17): $1.21 \mathrm{mmol}$ of the diamine and $2.42 \mathrm{mmol}$ of trimellitic anhydride were placed in $25 \mathrm{~mL}$ of acetic acid and the mixture stirred for $12 \mathrm{~h}$ at room temperature, and then refluxed for 3 $\mathrm{h}$. After this time, the acetic acid was distilled under reduced pressure, and the residue poured into $10 \% \mathrm{HCl}$. The white-color solid was filtered, washed with water and characterized.

I-Si: Yield: $96 \%$. M.p.: $178-180{ }^{\circ} \mathrm{C}$. IR ( $\left.\mathrm{KBr}\right)\left(\mathrm{cm}^{-1}\right): 3435(\mathrm{OH}), 3069(\mathrm{H}$ arom.), 1781, $1721(\mathrm{C}=\mathrm{O}), 1594,1504(\mathrm{C}=\mathrm{C}$ arom.), 854 (arom, 1,2,4-subst.), 825 (arom. $p$-subst.), 749, 701 (arom. mono-subst.). ${ }^{1} \mathrm{H}$ NMR (acetone- $d_{d}$ ) (d) (ppm): 7.44-7.79 (m, 18H, arom.), 8.07-8.12 (m,2H,arom.), 8.45 (m,2H,arom.) $8.52(\mathrm{~m}, 2 \mathrm{H}$, arom. $), 12.79(\mathrm{~s}, 2 \mathrm{H}, \mathrm{OH}) .{ }^{13} \mathrm{C}\left(\right.$ acetone- $\left.d_{6}\right)(\mathrm{d})(\mathrm{ppm}): 124.6,124.8$, 127.4, 128.1, 128.8, 129, 129.2, 129.8, 133.2, 133.4, 135.8, 136.4, 137.2, 137.7 (C arom.), 166.1, 167.1 (C=O). ${ }^{29} \mathrm{Si}$ (acetone- $d_{6}$ ) (d) (ppm): -14.2. Elemental analysis: Calc.: C: $66.44 \%$, H: $3.43 \%$, N: $3.69 \%$. Found: $66.53 \%$, H: $3.37 \%$, $\mathrm{N}: 3.74 \%$.

I-Ge: Yield: 87\%. M.p.: $190-192{ }^{\circ} \mathrm{C}$. IR $(\mathrm{KBr})\left(\mathrm{cm}^{-1}\right): 3430(\mathrm{OH}), 3070(\mathrm{H}$ arom.), 1781, $1722(\mathrm{C}=\mathrm{O}), 1596,1503(\mathrm{C}=\mathrm{C}$ arom.), 854 (arom. 1,2,4-subst.), 802 (arom. $p$-subst.), 751, 697 (arom. mono-subst.). ${ }^{1} \mathrm{H}$ NMR (DMSO- $d_{6}$ ) (d) 
(ppm): 7.46-7.56 (m,18H,arom.), 8.08 (d,2H,arom.), 8.09 (s,2H,arom.), 8.42 (d,2H,arom.), 12.56 (s,2H,OH). ${ }^{13} \mathrm{C}$ NMR (DMSO-d $)$ (d) (ppm): 123.7, 123.8 , $124.3,127.3,127.8,128.5,128.9,129.4,132.1,133.7,134.2,134.9,135.5$, 135.9, (C arom.), 166.3, $165.8(\mathrm{C}=\mathrm{O})$. Elemental analysis: Calc.: C: $70.59 \%$, H: $3.64 \%$, N: $3.92 \%$. Found: $70.66 \%$, H: 3.69\%, N: 3.99\%.

The diamines, bis(4-aminophenyl)diphenylsilane and bis(4-aminophenyl) diphenylgermane, were obtained from 4-bromo- $N, N$-bis(trimethylsilyl) aniline and diphenyldichlorosilane or diphenyldichlorogermane, respectively, according to a described procedure (18).

\section{Poly(imide-amides) (PIAs)}

PIAs were synthesized according to the following general procedure. The diacid I-Si or I-Ge $(0.152 \mathrm{mmol})$ and the respective diamine $(0.152 \mathrm{mmol})$ were mixed with $0.08 \mathrm{~mL}$ of triphenyl phosphite, $0.3 \mathrm{~mL}$ of $N$-methyl-2pyrrolidone, $0.08 \mathrm{~mL}$ of pyridine and $0.03 \mathrm{~g}$ of $\mathrm{CaCl}_{2}$, and the mixture heated at $110-120{ }^{\circ} \mathrm{C}$ for three hours. After this time, the mixture was poured into methanol and the precipitated polymer filtered, washed with methanol, dried at $40{ }^{\circ} \mathrm{C}$ under vacuum until constant weight and characterized.

PIA-I. IR ( $\mathrm{KBr})\left(\mathrm{cm}^{-1}\right): 3418(\mathrm{NH}), 3068$ ( $\mathrm{H}$ arom.), 1721 (C=O imide), $1672(\mathrm{C}=\mathrm{O}$ amide $), 1590,1502(\mathrm{C}=\mathrm{C}$ arom. $), 854$ (arom. 1,2,4-subst.), 820 (arom. $p$-subst.), 736, 699 (arom. mono-subst.). ${ }^{1} \mathrm{H}$ NMR (DMSO- $d_{6}$ ) (d) (ppm): 7.1-8.5 (m,42H,arom.), 10.6, 10.8 (s,2H,NH). ${ }^{13} \mathrm{C}$ NMR (DMSO-d $\left.d_{6}\right)$ (d) (ppm): 120.8, 121.1, 122.8, 124.1, 124.7, 126.3, 127.5, 127.8, 128.7, 128.8, $128.9,129.2,129.4,130.1,130.3,132.3,134.2,134.7,134.8,134.9,135.3$, $135.8(\mathrm{C}$ arom. $), 167(\mathrm{C}=\mathrm{O})$. Elemental analysis $\left(\mathrm{C}_{6} \mathrm{H}_{4} \mathrm{~N}_{4} \mathrm{O}_{2}\right)$ : Calc.: $\mathrm{C}$ : $69.89 \%$, H: $3.88 \%$, N: $4.94 \%$. Found: $68.70 \%$, H: $3.60 \%, \mathrm{~N}: 4.73 \%$.

PIA-II. IR (KBr) $\left(\mathrm{cm}^{-1}\right): 3388(\mathrm{NH}), 3068$ ( $\mathrm{H}$ arom. $), 1720(\mathrm{C}=\mathrm{O}$ imide $)$, $1676(\mathrm{C}=\mathrm{O}$ amide), 1590, $1503(\mathrm{C}=\mathrm{C}$ arom.), 853 (arom. 1,2,4-subst.), 823 (arom. $p$-subst.), 728, 699 (arom. mono-subst.). ${ }^{1} \mathrm{H}$ NMR (DMSO-d ) (d) (ppm): 7.1-8.5 (m,42H,arom.), 10.8 (s,2H,NH). ${ }^{13} \mathrm{C}$ NMR (DMSO-d $d_{6}$ (d) (ppm): 119.3, 120.6, 121.1, 122.8, 124.2, 127.8, 128.3, 128.7, 128.9, 129.4, $129.8,130.6,132.3,133.6,133.8,134.2,134.4,134.7,135,136.3,136.9$, $140.8(\mathrm{C}$ arom. $), 166.9,167(\mathrm{C}=\mathrm{O}) .{ }^{29} \mathrm{Si}$ NMR (DMSO-d $)(\mathrm{d})(\mathrm{ppm}):-15.22$. Elemental analysis $\left(\mathrm{C}_{6} \mathrm{H}, \mathrm{N}\right.$ O GeSi) : Calc.: C: $72.75 \%$, H: $4.02 \%$, N: $5.14 \%$. Found: $73.60 \%$, H: $3.90 \%, \mathrm{~N}$ : $5.01 \%$.

PIA-III. IR (KBr) $\left(\mathrm{cm}^{-1}\right): 3417(\mathrm{NH}), 3068$ ( $\mathrm{H}$ arom. $), 1723(\mathrm{C}=\mathrm{O}$ imide), $1676(\mathrm{C}=\mathrm{O}$ amide), 1592, $1503(\mathrm{C}=\mathrm{C}$ arom.), 855 (arom. 1,2,4-subst.), 821 (arom. $p$-subst.), 756, 700 (arom. mono-subst.) ${ }^{1} \mathrm{H}$ NMR (DMSO- $d$ ) (d) (ppm): 7.1-8.6 (m,42H,arom.), $10.6(\mathrm{~s}, 2 \mathrm{H}, \mathrm{NH}) .{ }^{13} \mathrm{C}$ NMR (DMSO- $\left.d_{6}\right)$ (d) (ppm): $120.1,120.3,121.1,122.3,122.8,124.2,127.2,128.9,129.2,129.4,129.5$, $130.1,130.6,134.2,134.3,134.8,134.9,135.3,135.9,136.4,136.8,136.9$ (C arom.), $166.9(\mathrm{C}=\mathrm{O}) .{ }^{29} \mathrm{Si}$ NMR (DMSO- $\left.d_{6}\right)(\mathrm{d})(\mathrm{ppm}):-14.66$. Elemental analysis $\left(\mathrm{C}_{6} \mathrm{H}_{4} \mathrm{~N} \mathrm{O} \mathrm{GeSi}\right)$ : Calc.: C: $72.75 \%$, H: $4.02 \%$, N: $5.14 \%$. Found: $71.50 \%$, H: $3.96 \%, \mathrm{~N}: 5.02 \%$.

PIA-IV. IR (KBr) $\left(\mathrm{cm}^{-1}\right)$ : $3418(\mathrm{NH}), 3068$ ( $\mathrm{H}$ arom. $), 1724(\mathrm{C}=\mathrm{O}$ imide), $1676(\mathrm{C}=\mathrm{O}$ amide), 1591, $1504(\mathrm{C}=\mathrm{C}$ arom.), 855 (arom. 1,2,4-subst.), 822 (arom. $p$-subst.), 726, 701 (arom. mono-subst.). ${ }^{1} \mathrm{H}$ NMR (DMSO-d $)$ (d) (ppm): 7.0-8.6 (m,42H,arom.), $10.8(\mathrm{~s}, 2 \mathrm{H}, \mathrm{NH}) .{ }^{13} \mathrm{C}$ NMR (DMSO- $\left.d_{6}\right)$ (d) (ppm): $120.3,120.7,122.3,122.8,124.1,126.2,126.3,127.2,127.8,128.4$ $128.7,128.8,129.4,129.8,130.1,130.6,133.9,134.4,135,135.5,136.3,137$ $\left(\mathrm{C}\right.$ arom.), 166.8, $167(\mathrm{C}=\mathrm{O}) .{ }^{29} \mathrm{Si}$ NMR (DMSO- $\left.d_{6}\right)(\mathrm{d})(\mathrm{ppm}):-14.64,-15.21$. Elemental analysis $\left(\mathrm{C}_{6} \mathrm{H}_{4} \mathrm{NO} \mathrm{Si}_{2}\right)$ : Calc.: C: $75.86 \%, \mathrm{H}: 4.21 \%$, N: $5.36 \%$. Found: $74.87 \%, \mathrm{H}: 4.02 \%$, N: $5.51 \%$.

\section{RESULTS AND DISCUSSION}

The diacids I-Si and I-Ge were obtained from trimellitic anhydride and the diamines bis(4-aminophenyl)diphenylsilane and bis(4-aminophenyl) diphenylgermane in acetic acid with good yields, according to a described procedure (18), and characterized by spectroscopic methods.

PIAs were synthesized directly from the diacids I-Si and I-Ge and the respective diamines, according to the triphenyl phosphite method (19) and heated at $110-120{ }^{\circ} \mathrm{C}$ for three hours. PIAs were precipitated in methanol, filtered, washed, dried and characterized by spectroscopic methods and elemental analysis. The results are shown in the Experimental Part and they are in agreement with the proposed structures. Figure 1 shows the synthetic scheme of both, the diacids and the PIAs. In particular, the ${ }^{29} \mathrm{Si}$ NMR spectra showed the signals corresponding to the $\mathrm{Si}$ atom bonded to four aromatic rings at $-15 \mathrm{ppm}$ approximately, which has been described for other monomers and polymers containing similar residues in the main chain (20).

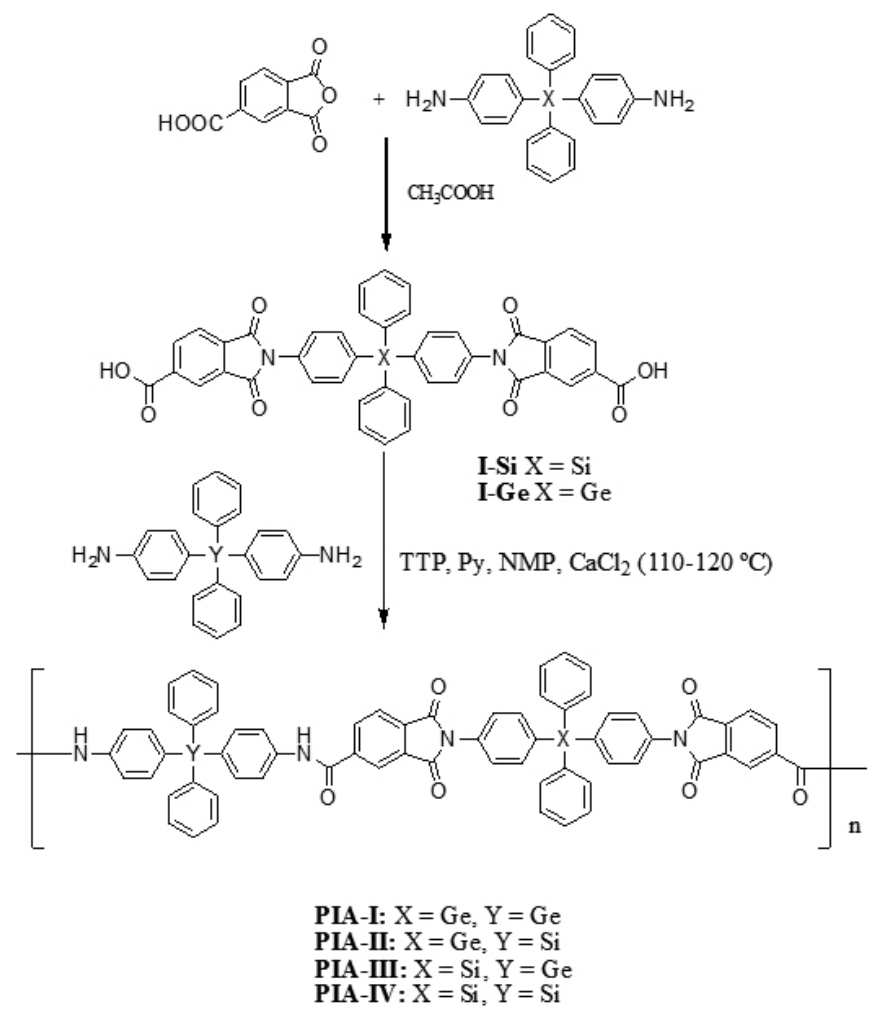

Figure 1. Synthetic scheme of the diacids and the poly(imide-amides)

PIAs were soluble in aprotic polar solvents, such as dimethylsulfoxide, $N, N$-dimethylformamide, $m$-cresol and $N, N$-dimethylacetamide.

Table I shows the yields. These parameters are good but with low $h_{\text {inh }}$ values, being probably PIAs of oligomeric nature of low molecular weight, especially PIA-I and PIA-III derived from the diamine containing germanium as central atom. We do not have a clear explanation about this behavior; however a possible reason could be related to the electronegativity of these heteroatoms. In fact, Ge has higher electronegativity than $\mathrm{Si}$ (5), and the electron pair of the nitrogen atom of the amine group can be more delocalized in relation to the amine with $\mathrm{Si}$. This situation would make the diamine with $\mathrm{Ge}$ less reactive than that with $\mathrm{Si}$, and consequently PIAs with this diamine would have lower molecular weight.

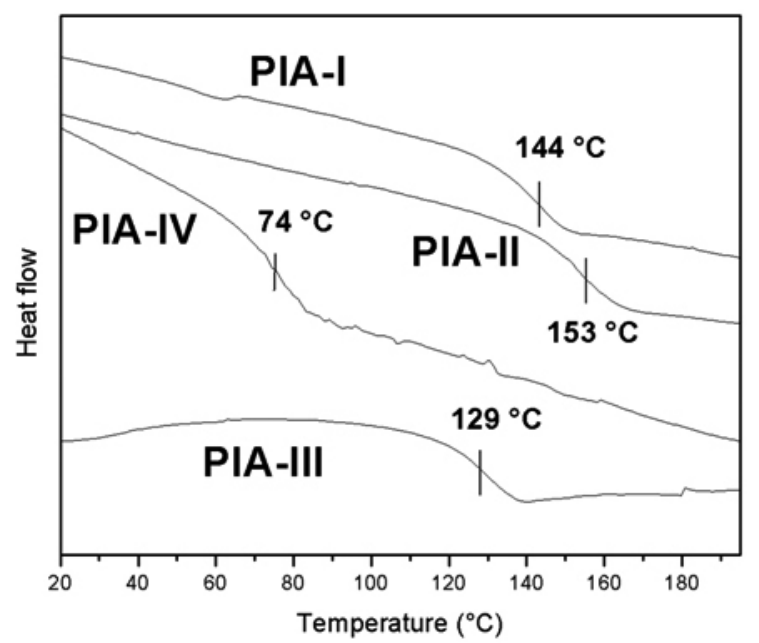

Figure 2. DSC curves of the poly(imide-amides). 
Table I also shows the Tg values, and figure 2 the DSC thermograms, considering the change of the slope of the curve. The only structural difference between the PIAs is the nature of the heteroatoms in the main chain. If we consider that the $\mathrm{Ge}$ atom has higher size than $\mathrm{Si}$, which implies that the $\mathrm{C}-\mathrm{Ge}$ bond is longer than C-Si, PIAs with $\mathrm{Si}$ would have higher Tg values than those with $\mathrm{Ge}$, due to the lower rotation barriers of the $\mathrm{C}-\mathrm{Ge}$ bonds. Considering the Tg values of these PIAs, it can be deduced that there is not a relation in agreement with the first statement. The higher Tg value corresponds to PIA-II with one Si atom, which would be similar to that of PIA-III. PIA-IV should have the highest $\mathrm{Tg}$ value, but it showed the lowest. One possible explanation can be the low values of the $\eta_{\text {inh }}$, associated to low molecular weights, which is an important parameter in the Tg values.

Table I.- Yields, $\eta_{\text {inh }}$, glass transition temperatures $(\mathrm{Tg})$ and thermal decomposition temperatures (TDT) of the PIAs

\begin{tabular}{|c|c|c|c|c|c|c|}
\hline & Yield (\%) & X & Y & $\eta_{\text {inh }}(d L / g)^{*}$ & $\operatorname{Tg}\left({ }^{\circ} \mathrm{C}\right)$ & $\mathrm{TDT}^{* *}\left({ }^{\circ} \mathrm{C}\right)$ \\
\hline PIA-I & 67 & $\mathrm{Ge}$ & $\mathrm{Ge}$ & 0.04 & 144 & 357 \\
\hline PIA-II & 68 & $\mathrm{Ge}$ & $\mathrm{Si}$ & 0.12 & 53 & 416 \\
\hline PIA-III & 64 & $\mathrm{Si}$ & $\mathrm{Ge}$ & 0.04 & 129 & 405 \\
\hline PIA-IV & 85 & $\mathrm{Si}$ & $\mathrm{Si}$ & 0.07 & 74 & 345 \\
\hline
\end{tabular}

* Inherent viscosity, in DMSO at $25^{\circ} \mathrm{C}(\mathrm{c}=0.3 \mathrm{~g} / \mathrm{dL})$

** $10 \%$ weight loss temperature

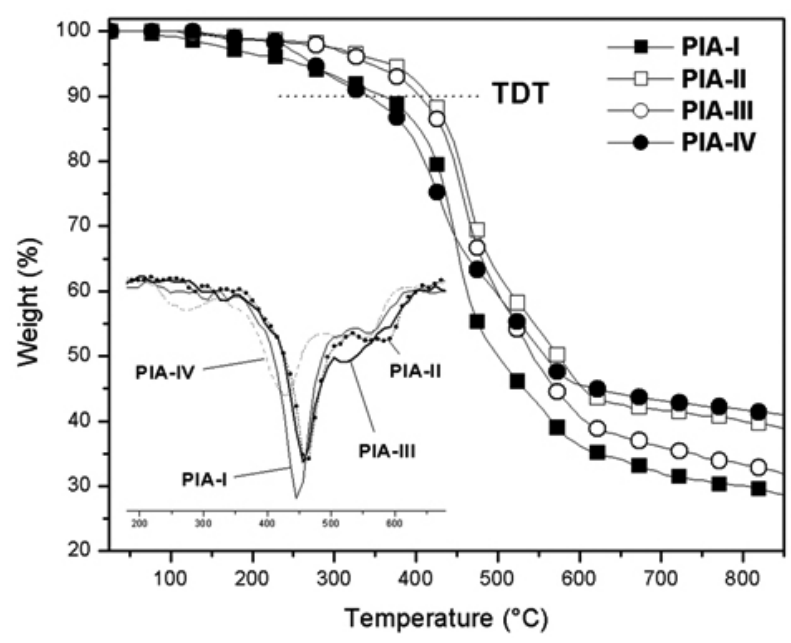

Figure 3. Thermogravimetric curves of the poly(imide-amides)

Table I shows the thermal decomposition temperatures (TDT), taken as the temperature at which the weight loss is $10 \%$, and figure 3 the thermogravimetric curves. It has been reported that the bond polarity has influence on the thermal stability, in the sense that when the chain polarity increases, the thermal stability also increases (4). In this case, the only difference between the PIAs is the nature of the heteroatom. The polarity of the $\mathrm{C}$-Si bond is greater than that of $\mathrm{C}-\mathrm{Ge}$, since $\mathrm{Si}$ has lower electronegativity than $\mathrm{Ge}$, and as a consequence, polymers with $\mathrm{Si}$ atom would have higher TDT than those with Ge. PIA-II and PIA-III, with one Si atom, showed similar TDT values. PIA-I with only Ge atoms showed a lower value than PIA-II and PIA-III. However, PIA-IV with two $\mathrm{Si}$ atoms should have the higher TDT value, but has the lowest one. The only reason can be the low molecular weight, which causes a fast breaking of the polymeric chain. Nonetheless, two PIAs showed TDT values higher than $400{ }^{\circ} \mathrm{C}$, and can be considered as thermally stable. The residue after heating at $900{ }^{\circ} \mathrm{C}$ are between $26-44 \%$ corresponding probably to silicon oxide.

\section{CONCLUSIONS}

Four poly(imide-amides) of low molecular weight and containing two heteroatoms, Si and/or Ge, in the main chain were synthesized from the diacids obtained from trimellitic anhydride and the diamines bis(4-aminophenyl) diphenylsilane or that with germane. These diacids were reacted with the same diamines in order to obtain the PIAs. The yields were good but the $\eta_{\text {inh }}$ values were low, indicating that polymers were of oligomeric nature of low molecular weight. The Tg values did not show the tendency in the sense that PIAs with $\mathrm{Si}$ should have higher values of this parameter than those with Ge, due to the longer length of the $\mathrm{C}-\mathrm{Ge}$ bond. This is probably due to the low molecular weights of these polymers. The TDT values, influenced by the nature of the heteroatom and consequently by the polarity of the C-Si or C-Ge bonds, showed the normal tendency in the sense that PIA-II and PIA-III, with one Si atom, showed higher TDT values than PIA-I with only Ge atoms. The exception was PIA-IV with two Si atoms in its repetitive unit, which showed the lowest TDT value, probably due to the low molecular weight.

\section{ACKNOWLEDGEMENTS}

Authors acknowledge the financial assistance to this work by Fondo Nacional de Investigación Científica y Tecnológica, FONDECYT, through Project 1070778 .

\section{REFERENCES}

1 Sava, I.; Bruma, M.; Schulz, B.; Mercer, F.; Reddy, V.N.; Belomoina, N. M. J. Appl. Polym. Sci. 65, 1533 (1997),

2 Wilson, D.; Stenzenberger, H.D.; Hergenrother, P.M. Polymimides, (1990), Blackie, London.

3 Ghosh, M.K.; Mittal, K.L. Polyimides: Fundamentals and Applications, (1996), Marcel Dekker, New York.

4 Bruma, M.; Hamciuc, E.; Sava, I.; Belomoina, N.M. Russ. Chem. Bull. Int. Ed. 531813 (2004)

5 The Periodic Table on the web http://www.webelements.com

6 Sava, I.; Bruma, M.; Schulz, B.; Kopnick, T. High Perform. Polym. 17, 483 (2005).

7 Li, F.; Ge, J.J.; Honigfort, P.S.; Fang, S.; Chen, J.C.; Harris, F.W.; Cheng, S.Z.D. Polymer 4, 4987 (1999).

8 Hamciuc, C.; Hamciuc, E.; Bruma, M. Mater. Plast. 35, 75 (1998),

9 Tagle, L.H.; Terraza, C.A.; Leiva, A.; Alvarez, P. e-Polymers, $\mathrm{N}^{\circ} 034$ (2009).

10 Tagle, L.H.; Terraza, C.A., Leiva, A.; Yazigi, N.; López, L. J. Appl. Polym. Sci. 117, 1526 (2010).

11 Terraza, C.A.; Tagle, L.H.; Leiva, A. Polym. Bull., 63, 663 (2009).

12 Tagle, L.H.; Terraza, C.A.; Leiva, A.; Alvarez, P. J. Appl. Polym. Sci., 114, 1080 (2009)

13 Terraza, C.A.; Tagle, L.H.; Leiva, A.; Poblete, L.; Concha, F.J. J. Appl. Polym. Sci., 109, 303 (2008).

14 Terraza, C.A.; Tagle, L.H.; Leiva, A.; Valenzuela, P. J. Appl. Polym. Sci., 102, 2768 (2006).

15 Tagle, L.H.; Terraza, C.A.; A.; Alvarez, P.; Vega, J.C. J. Macromol. Sci., Part A, Pure Appl. Chem., 42, 301 (2005).

16 Tagle, L.H. Macromol. Symp. 199, 499 (2003), and the references therein

17 Faghihi, K.; Gholizadeh, M. Turk. J. Chem. 33, 87 (2009).

18 Pratt, J.R.; Massey, W. D.; Pinkerton, F. H., Thames, S. F. J. Org. Chem. 40, 1090 (1975).

19 Yamazaki, N.; Matsumoto, M., Higashi, F. J. Polym. Sci. Polym. Chem. Ed. 13, 1373 (1975).

20 Tundidor-Camba, A.; Terraza, C.A., Tagle, L.H.; Coll, D. J. Appl. Polym. Sci. 120, 2381 (2011). 